company), two groups were formed: one for low and one for higher high exposure. Thirteen neuropsychological tests evaluated cognitive, motor, and four evaluated affective aspects.

Results Means were for: age 35(9.14) years; time working at the company $8(8.6)$ years. In the multiple linear regression models decreased function was confirmed only for two tests: trailmaking A $\left(\mathrm{R}^{2}=12.3 \%\right)$ and Pursuit aiming II $\left(\mathrm{R}^{2}=19.5 \%\right)$. Age contributed to this and higher education level improved performance.

Conclusions Slight alterations were observed in this population exposed to low OS concentrations. However, it is necessary to improve cumulative exposure measurement and identify the best, most sensitive neuropsychological tests.

\section{RELATIONSHIP BETWEEN WORKING CONDITION AND HEALTH-RELATED QUALITY OF LIFE AMONG KOREAN SCHOOL COOKS FOR LUNCH SERVICES}

${ }^{1} \mathrm{M}$ Choi, 'Lee, ${ }^{2}$ Lee, ${ }^{2}$ Kim. ${ }^{1}$ Seoul St. Mary's Hospital, Seoul, South Korea; ${ }^{2}$ Korea Institute of Labor Safety and Health, Seoul, South Korea

\subsection{6/oemed-2013-101717.145}

Objectives This paper investigates the health-related quality of life (HQOL) among Korean school cooks for lunch services, especially focusing on the relationship between working conditions and their physical and mental HQOL.

Methods A cross-sectional study of 1,397 school cooks in one province was carried out, using a mail survey from June to October 2012. Working conditions and HQOL were determined through structured self reported questionnaires.

To evaluate working conditions, subjective labour intensity was investigated using Borg scale, and the numbers of both daily working hours and meals assigned per cook were questioned. HQOL was determined by applying 'Korean SF-8.'

To evaluate the degree of association between working conditions and HQOL, odds ratios were estimated after adjusting for demographic factors, such as age, education, chronic disease, exercise and drinking habits by logistic regression.

Results All of respondents were female, and the mean age was 47.8 (S. D = 5.36).

School cooks assigned more than 120 meals showed statistically significantly lower HQOL scores both in physical $(\mathrm{OR}=$ $1.48,95 \% \mathrm{CI}=1.03-2.13)$ and mental $(\mathrm{OR}=1.47,95 \% \mathrm{CI}=$ 1.03-2.10) criteria than those who were assigned less than 90 .

Workers who responded that 'My work is hard' $(13 \leq$ Borg scale $\leq 16)$ or 'My work is very hard' $(17 \leq$ Borg scale $\leq 20)$ have significantly lower physical $(\mathrm{OR}=3.47,95 \% \mathrm{CI}=2.47-4.86)$ and mental $(\mathrm{OR}=1.88,95 \% \mathrm{CI}=1.36-2.59)$ HQOL scores than those who did not $(6 \leq$ Borg scale $\leq 12)$.

The number of daily working hours was not significantly related to physical and mental HQOL scores.

Conclusions The degree of subjective labour intensity and the number of meals assigned per cook were related to the physical and mental HQOL of school cooks for lunch services.

Since cooks assigned more than 120 meals have significantly lower physical and mental HQOL scores, the number of lunch meals assigned per cook should be reduced.

\section{NIGHT SHIFT WORK AND HEALTH STATUS OF WORKERS EMPLOYED IN INDUSTRIAL PLANTS. PRELIMINARY RESULTS}

W B Burdelak, Peplonska, Bukowska, Krysicka. Nofer Institute of Occupational Medicine, Lodz, Poland

\subsection{6/oemed-2013-101717.146}

Objective Night shift work has been linked to a higher incidence of some chronic diseases such as gastrointestinal or cardiovascular diseases. This is the first study assessing the prevalence of selected diseases and symptoms among middle-aged Polish night shift workers.

Methods We conducted a cross-sectional study of 605 blue collar workers in plants operating based on a shift system in Łódz', Poland. The study included 434 night shifts workers and 171 day-only workers (369 men and 236 women), aged 35-65. The employees coming to a periodic health examination to occupational physicians were invited to participate in the study. The data were collected via a self-administered questionnaire based on the "Standard Shiftwork Index". Crude frequencies of occurrence of particular diseases and symptoms were calculated.

Results The mean age of the night shift workers and the day workers were similar, i.e. 47.6 and 46.6 years, respectively $(\mathrm{p}=$ $0.13)$. Hypertension (14.7\%), high cholesterol/hypercholesterolemia $(10.9 \%)$ and chronic back pain $(10.9 \%)$ were the most common diseases in this population. The prevalence of hypertension (14.3\% among the night shift workers) and gastric ulcer (6.0\%) was slightly higher than in the general population in Poland in a similar age group (hypertension $\sim 12 \%$ and gastric ulcer $\sim 4 \%$ ). The prevalence of irritable bowel syndrome (IBS) (1.2\% among the night shift workers), coronary heart disease (CHD) (1.2\%) and high cholesterol (9.9\%) were slightly lower among the industrial workers compared to the general population in Poland (IBS $\sim 13 \%, \mathrm{CHD} \sim 5 \%$ and high cholesterol $\sim 60 \%$ ).

Conclusions Our study suggest some associations among Polish workers for the diseases potentially linked to night shift work, however further analyses are necessary (with adjustment for important confounders) to confirm these preliminary findings.

\section{DESCRIPTION OF WORK ACCIDENTS IN SERIOUS CONDITION PARANÁ - SOUTHERN BRAZIL}

${ }^{1}$ La S Aracema Scussiato, ${ }^{2}$ V E A F Felli. ${ }^{1}$ Curitiba, Brazil; ${ }^{2}$ University of Sao Paulo - School of Nursing, Sao Paulo, Brazil

\subsection{6/oemed-2013-101717.147}

Objective Characterise serious occupational accidents occurred in the state of Paraná between 2007 and 2010.

Methods This is a descriptive epidemiological study design, cross-sectional and retrospective type, which covered the area of the state of Paraná, southern Brazil. Data source was the Sistema de Informação de Agravos de Notificação (Brazilian Case Registry Database). The inclusion criterion was being a worker aged 16 to 65 years. We have selected 24 variables and the data analysis followed descriptive statistics.

Results Between 2007 and 2010, were 4354 notifications, with an increase in records number as the years progressed. Regarding to the workers profile, $88.36 \%$ were male, predominantly Caucasian (69.66\%), 21.52\% finished secondary school, and $17.16 \%$ were between 26 and 30 years. Most affected occupations were among workers in mining industry and construction (13.85\%), production of consumer goods and industrial services $(13.37 \%)$ and services workers, safety and security, selling at stores (11.97\%). Regarding to work situation, $70.88 \%$ of workers had a formal contract, however, the CAT (employment 
record card) was issued in only $59.26 \%$ of cases. Regarding to the accidents, $58.45 \%$ occurred in employer's facilities, during the day, predominantly between 9 and $10 \mathrm{am}$. Of those, $73.95 \%$ were typical, $21.54 \%$ were in transit, and almost all (94.64\%) of injured workers needed medical attention. The accidents were mainly caused by external causes of accidental injury (53.10\%) and by accidents $(24.58 \%)$. Most affected body parts were hands (37.16\%). About cases evolution, $56.38 \%$ of workers were temporarily disabled and $9.74 \%$ died due to the accident.

Conclusions Accidents at work cause serious social and economic damages, mental and emotional harm to workers, their family and dependents. To the Public Health, accidents at work involve spending on emergency, assistance, and rehabilitation; to country's economy, workers in productive age are lost.

\section{RELATIONS BETWEEN WORK ENVIRONMENT FACTORS, BURNOUT AND HEALTH OF THE MILITARY PERSONNEL}

E M Merisalu, Viin, Vähi, Jõgeva, Orru. University of Tartu, Tartu, Estonia

10.1136/oemed-2013-101717.148

Aim The purpose of present study was to examine relations between work environment factors, burnout and state of health of the military personnel and to find factors that can affect the level of burnout and adverse health status.

Method The data has been gathered by the anonymous questionnaire in 2008-2009. The target group consisted of 3199 military men. Six structural units were included into the study. Results Study group consisted of 641 persons, whereas $45 \%$ of them were servants, $31 \%$ executive officers and $20 \%$ officers (4\% unknown). $55 \%$ of respondents were female (mainly servants) and 44\% men (mainly officers). The average age of the study group was 39 years (SD 11) and their average work experience 6 years ( $\max 40 \mathrm{yrs}$ ).

In general military personnel found their health to be good and they were fairly satisfied with their working environment. But the respondents with higher burnout levels assessed more negatively their work environment and health status. They perceived more often work-family conflict, lack of instructions, lower appreciation and less internest toward work. Also, they measured deeper tiredness and depression and more psycosomatic disorders. Male officers and female servants were more negative in their answers than male noncommissioned officers and male servants.

Conclusions That to prevent burnout and health problems among military personnel it is needful to pay more attention on work environment and work organisation.

\section{Session: T. Intervention studies \& health management}

\section{IMPROVING THE IMPACT: RECOMMENDATIONS FOR THE USE OF CLEANING CHEMICALS}

${ }^{1} \mathrm{P}$ K Henneberger, ${ }^{2} \mathrm{~K}$ Fagan, ${ }^{1} \mathrm{~S}$ A Henn. ${ }^{1}$ National Institute for Occupational Safety and Health, Morgantown, WV, United States of America; ${ }^{2}$ Occupational Safety and Health Administration, Washington, DC, United States of America

10.1136/oemed-2013-101717.149

Objectives Cleaning chemicals are commonly used in the occupational environment and have been associated with increased risks of asthma, upper and lower respiratory symptoms, and dermatitis. It is important that cleaning workers use appropriate products safely. The Occupational Safety and Health Administration (OSHA) and the National Institute for Occupational Safety and Health (NIOSH) in the United States collaborated to develop educational materials targeted at workers that use cleaning chemicals and their employers.

Methods OSHA and NIOSH staff used published data about cleaning chemicals to guide the content of an information sheet and poster, sought input from industry, unions, government and academia, and developed plans for dissemination of these educational materials.

Results The information sheet and poster were released to the public in 2012 and are electronically available on the OSHA and NIOSH websites. The information sheet, developed for employers, is 6 pages and includes sections on choosing safer cleaning chemicals, safer work practices, worker training, and resources, including numerous links to sites on the internet that have additional information. The poster, developed for workers, alerts workers to the potentially harmful effects of cleaning chemicals and what they need to know to work safely with these chemicals. The poster, originally in English, has been translated into Spanish, Chinese, and Tagalog, and can be printed in varying sizes. The educational materials were disseminated through a network of partnerships created by the NIOSH National Occupational Research Agenda that included unions, safety and health professionals, worker organizations, academia, and government agencies.

Conclusions The information sheet and poster have filled a need for clear communication about chemical cleaners that workers handle every day. Efforts to further disseminate these materials are still underway. Additional feedback from stakeholders will determine if additional translated languages are needed.

\section{INDEPENDENT MEDICAL EVALUATIONS: A SYSTEMATIC REVIEW}

1J W B Busse, 'Ebrahim, ${ }^{2}$ Mahood, 'Guyatt, ${ }^{3}$ Kunz. ${ }^{1}$ McMaster University, Hamilton, Canada; ${ }^{2}$ nnstitute for Work \& Health, Toronto, Canada; ${ }^{3}$ University Hospital Basel, Basel, Switzerland

\subsection{6/oemed-2013-101717.150}

Objective Individuals suffering an injury or illness may be eligible to receive financial compensation based on their level of impairment and an independent medical evaluation (IME) often guides this determination. Our objectives are to determine the issues authors have addressed and their viewpoints, establish where evidence allows for recommendations regarding the best practices for IMEs, identify important gaps, and provide guidance on priorities for future research.

Methods We conducted a systematic review of all literature regarding IMEs conducted in a North American setting.

Results We identified 4667 potentially eligible studies; we retrieved 129 studies in full text and 88 proved eligible. We located another 22 eligible articles from bibliography searches. The chance-independent between-reviewer agreement (phi) on full text eligibility was 0.84 . The majority of studies $(81 \% ; 89$ of 110) were narrative reviews.

We found that authors of narrative reviews are much more likely to express favourable views if they perform IMEs, work for a company that arranges these assessments, or work in an area in which IMEs disputing patient's reported level of impairment are likely to be helpful (Pearson correlation coefficient $=$ $0.70, \mathrm{p}<0.001)$. The 8 reasons provided for which IMEs are 